\title{
Políticas públicas y turismo en Argentina, 1955-1983. Una lectura desde las ideologías derechistas ${ }^{\star}$
}

Daniela I. Castellucci ${ }^{\star \star}$

\begin{abstract}
ReSUMEN
El aRTíCULO TIENE COMO OBJETIVO IDENTIFICAR Y ANALIZAR LAS IDEAS DERECHISTAS EN LAS POLítiCAS PÚBLICAS EN MATERIA de tURismo implementadas POR los gobiernos nacionAles de Argentina, deSde 1955 haSta 1983. Para su Cumplimiento se realiza un estudio de Carácter descriptivo e INTERPRetativo a PartiR del ANÁlisis DOCUMENTAL Y DE CONTENIDO DE DIFERENTES INSTRUMENTOS DE POLÍTICA PÚBLICA, COMO PLANES Y LEGISLACIÓN NACIONAL, A LA VEZ QUE SE HA COMPLEMENTADO CON OTROS DOCUMENTOS DE INSTITUCIONES PÚBLICAS. LA PRODUCCIÓN

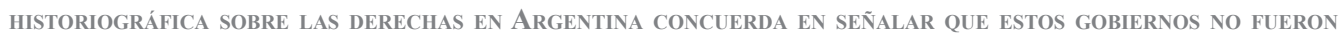
CUERPOS MONOLÍTICOS NI HOMOGÉNEOS, TODO LO CONTRARIO, Y CON ELLO TAMBIÉN SUS POLÍTICAS PÚBLICAS. A PARTIR DE LOS DOCUMENTOS ANALIZADOS SE OBSERVA QUE ES DURANTE EL PERÍODO 1955-1983 DONDE NO SÓLO SE INCORPORA AL TURISMO EN LA AGENDA POLÍTICA del PAís, SINO TAMBIÉN QUE ADQUIERE UN NUEVO SIGNIFICADO EN LA POLÍTICA DESDE UNA PERSPECTIVA PRINCIPALMENTE ECONÓMICA. EN DEFINITIVA, EL CAMBIO EN LA CONCEPCIÓN DEL TURISMO COMO POLÍTICA PÚBLICA HABRÍA SIDO IMPULSADO DESDE UN IDEARIO DERECHISTA CON UNA PREEMINENCIA DEL TIPO LIBERAL, ESPECIALMENTE EN LA FAZ ECONÓMICA, POR SOBRE EL DE CORTE NACIONALISTA, PARTICULARMENTE EN LA FAZ SOCIAL.

Palabras clave: Política pública - turismo - derechas - historia - Argentina.
\end{abstract}

Public Policies and Tourism in Argentina, 1955-1983. A Reading From the Right Wing Perspective

\section{Abstract}

The OBJECTIVE OF THE ARTICLE IS TO IDENTIFY AND ANALYZE THE RIGHTIST IDEAS IN PUBLIC POLICIES IN TOURISM MAterials implemented by the national governments of Argentina from 1955 to 1983. A descriptive and INTERPRETIVE STUDY IS MADE FROM ANALYSIS OF DOCUMENTS AND CONTENT OF DIFFERENT PUBLIC POLICY INSTRUMENTS, SUCH AS PLANS AND NATIONAL LEGISLATION, SUPPLEMENTED WITH OTHER DOCUMENTS FROM PUBLIC INSTITUTIONS. Historiographic production about Rights in ARgentina COINCIDES IN POINTING OUT THAT THESE GOVERNMENTS WERE NOT MONOLITHIC OR HOMOGENOUS BODIES, BUT QUITE THE CONTRARY; AND WITH THIS, SO WERE THEIR PUBLIC POLICIES. From THE ANALYZED DOCUMENTS IT IS OBSERVED THAT DURING THE PERIOD 1955-1983, TOURISM IS NOT ONLY INCORPORATED INTO THE POLITICAL AGENDA OF THE COUNTRY, BUT IT ALSO ACQUIRES A NEW MEANING IN POLITICS FROM A MAINLY ECONOMIC PERSPECTIVE. IN SHORT, THE CHANGE IN THE CONCEPTION OF TOURISM IN PUBLIC POLICY WOULD HAVE BEEN DRIVEN FROM A RIGHTIST IDEOLOGY OF LIBERAL CHARACTER, ESPECIALLY IN THE ECONOMIC REALM, OVER THE NATIONALIST ONE, PARTICULARLY IN THE SOCIAL SENSE.

Keywords: Public POlicy - tourism - Right-Wing POlitics - history - Argentina.

* Una versión preliminar del presente artículo se presentó en el VII Congreso Latinoamericano de Investigación Turística, 2 al 5 de agosto de 2016. Quito, Ecuador.

** Centro de Investigaciones Económicas y Sociales, Facultad de Ciencias Económicas y Sociales, Universidad Nacional de Mar del Plata (UNMdP). Licenciada en turismo y Magíster en desarrollo turístico sustentable. Doctoranda en historia (UNMdP). Profesora Adjunta. Investigadora, categoría III. Correo electrónico: daniela_castellucci@hotmailcom. 


\section{Introducción}

$\mathrm{D}$ esde la caída del peronismo en 1955 hasta la primera década del siglo XXI, la historia argentina se ha caracterizado por la inestabilidad y el desacuerdo, afectando y haciendo más complejos los procesos políticos, económicos, sociales y culturales. En la búsqueda de lograr un régimen político legítimo y estable, y políticas públicas que aseguren el progreso económico y social del país, se fueron ensayando diferentes regímenes democráticos, semidemocráticos y autoritarios (Novaro, 2013), en los cuales primaron las ideas derechistas en sus diversas tradiciones.

En este contexto, el presente estudio se centra en el análisis de las políticas públicas en materia de turismo implementadas por los gobiernos de derecha en Argentina, durante gran parte de la segunda mitad del siglo XX. Se aborda la política turística en este país durante el período 19551983 dado que este lapso representa la institucionalización del turismo en la agenda pública del país y también su resignificación desde una perspectiva económica a partir del golpe de Estado de 1955, tal como lo expresan Capanegra (2015) y Shenkel (2013). Así como sucedió en otros países, durante este período en Argentina se produce un cambio en el modo de pensar, construir e implementar políticas públicas para desarrollar el turismo, a partir de las doctrinas emanadas desde los organismos internacionales que habían comenzado a concebir al turismo como factor de desarrollo (Capanegra, 2011).

Es así que durante este período en los distintos gobiernos argentinos primaron las ideas derechistas. La derecha se ha asociado a la idea que las diferencias entre los hombres formarían parte de cierto "orden natural" en contraposición a la izquierda que las ha asociado con las relaciones sociales. Asimismo, dentro de las derechas se diferencia a los "moderados" de los "extremistas", distinción frecuentemente utilizada por gran parte de los estudios existentes sobre ideas políticas en Argentina. De esta manera se ha asociado, dentro del campo más general de "la derecha", a los "liberales" con las tendencias moderadas y a los "nacionalistas" con las posiciones más extremas. Si bien existe un importante acuerdo en identificar la escisión entre las fracciones liberal y nacionalista de la derecha argentina hacia los años treinta, resulta más complejo acordar una definición específica de cada fracción para el período posterior (Canelo, 2008).

En el presente estudio se tomará la caracterización que plantea Paul Lewis (2001 en Canelo, 2008) sobre las derechas. Para este autor los "nacionalistas" presentarían un perfil más corporativo y militarista, defensor de la herencia hispánica y de una alianza entre Iglesia y Ejército, mientras que los "liberales" serían partidarios de una visión restringida de democracia, se identificarían con el cosmopolitismo y promoverían la integración de la economía argentina con el mundo occidental. Los primeros inculparían a los liberales su vinculación con los intereses foráneos y su responsabilidad por un sistema económico que divide a la Nación en antagonismos de clase. Mientras que éstos acusarían a los nacionalistas de perpetuar el carácter subdesarrollado y cerrado de la economía, y de integrar instituciones y grupos autoritarios de retórica y práctica violenta. Por último, los liberales mostrarían una tendencia a desempeñarse como economistas, ingenieros o administradores, en contraposición con la orientación literaria general de los nacionalistas.

En cuanto al estado de la cuestión, la revisión de la literatura revela que en la historiografía internacional, el turismo ha sido objeto de atención académica desde hace varias décadas (Pastoriza, 2012). En América Latina, y en particular en Argentina, el interés en torno al turismo ha sido más reciente y los estudios han sido llevados a cabo principalmente por los historiadores sociales, aunque también se advierten trabajos realizados por especialistas de otras disciplinas con un enfoque sociológico, antropológico, económico o geográfico. En este país, han sido muy pocos los estudios sobre la política turística nacional, provincial o municipal. En este sentido, se destacan las investigaciones sobre las políticas turísticas en Argentina desde fines del siglo XIX hasta mitad del XX realizadas por Capanegra (2010, 2011, 2015), Pastoriza (2002, 2011), Piglia 
(2011, 2012, 2014) y Schenkel (2013). Respecto de los antecedentes de investigaciones sobre las derechas en los países del cono sur, se observa una interesante producción principalmente de estudios comparados (Bohoslavsky, 2009; Buchrucker, 2003; Mc Gee Deutsch, 1997). En particular, sobre los gobiernos militares y las derechas, también se encuentra una extensa producción entre las que se destacan el trabajo de Canelo (2008) en Argentina; Castagnola y Mieres (1996) en Uruguay; y Borges (2007) y Oliveira (2008) en Brasil.

A partir del marco bibliográfico producido en Argentina, se plantea el presente estudio que busca identificar y analizar las ideas derechistas en las políticas públicas en materia de turismo implementadas por los gobiernos nacionales de Argentina, desde 1955 hasta 1983. En función de este objetivo se realiza un estudio de carácter descriptivo e interpretativo. Se efectúa un análisis documental y de contenido de diferentes instrumentos de política pública, como planes y legislación nacional, a la vez que se ha complementado con otros documentos de instituciones públicas, localizados hasta el momento. En cuanto al desarrollo del trabajo el período analizado se ha estudiado en tres momentos: el primero recorre los años 19551966 donde se observan las primeras manifestaciones en las políticas públicas del cambio de concepción del turismo como factor de desarrollo para el país. El segundo momento, comprende el período 1966-1976, cuando definitivamente se institucionaliza esta concepción de los organismos internacionales y el turismo internacional se resignifica como política económica y se plantea su planificación. Y el tercer momento comprende el período 19761983, correspondiente al Proceso de Reorganización Nacional, cuando el turismo queda sin el andamiaje de la planificación sectorial.

\section{5-1966: el desarrollismo en la política turística}

En el golpe de Estado de septiembre de 1955, llamada "Revolución Libertadora", los civiles y militares que participaron del derrocamiento de Juan Domingo Perón estaban divididos en dos sectores. Por un lado estaban los "nacionalistas" y católicos que rodeaban al General Lonardi, quienes entendían que los conflictos que habían debilitado al gobierno de Perón se debían, primordialmente, a los vicios y errores de su líder, sobre todo aquellos que los habían enfrentado a la iglesia católica. Incluso algunos peronistas compartían esta opinión. Por otro lado, estaban los "liberales", quienes consideraban que el peronismo había dado origen a un estado autoritario, corporativo y corrupto que al igual que los aparatos sindicales, debía ser desterrado. Se trataba de desarmar todo el sistema de poder para que el país volviera a la normalidad (Novaro, 2013).

Más allá de las diferencias entre estas dos fracciones dentro del sector castrense, en definitiva los militares se concentraron en evitar el retorno del peronismo al poder y en combatir a la "subversión" promovida desde el exterior. En función de estos objetivos adoptaron la doctrina de la Seguridad Nacional, cuya tesis principal era la siguiente: primero que la "subversión" constituía un enemigo oculto y que formaba parte de una conspiración mundial del comunismo en contra de Occidente. En segundo lugar, que el desarrollo económico y la seguridad nacional estaban vinculados entre sí y que las Fuerzas Armadas no podían implementar el primero sin el último; y en tercer lugar, los militares tenían el derecho de supervisar y controlar a los gobiernos civiles y hasta de derrocarlos si estos fracasaban (Rock, 1993).

Apenas Lonardi asumió la presidencia de la Nación en septiembre de 1955, se dispuso a tomar el control del movimiento peronista bajo la consigna "ni vencedores ni vencidos" con una clara intención política conciliatoria. Esta actitud le valió la oposición de la fracción liberal de su gobierno, llena de odios y deseos de venganza, de los partidos políticos y de los empresarios que aspiraban a una depuración eliminando todo rastro de peronismo. En noviembre, a dos meses del golpe, el General Lonardi fue obligado a renunciar y asumió como presidente de la Nación el General Aramburu, de pertenencia ideológica de derecha liberal. Decidido a eliminar todo vestigio de peronismo y argumentando defensa de la democracia, Aramburu disolvió al partido peronista y todo aquello que lo vinculaba, intervino la CGT, y anuló por decreto la Constitución 
Nacional de 1949 reinstalando la de 1853. De este modo, se dio inicio a una reingeniería institucional, represiva y supuestamente pedagógica; así, los obreros y militantes sindicales del peronismo no debían ser perseguidos, sino reeducados (Novaro, 2013).

Ahora bien, en lo que respecta al turismo en este período ${ }^{1}$, el cambio en la conducción del país devino también en un giro en la forma de concebirlo y estructurarlo. Así, con el derrocamiento del peronismo, por un lado, el turismo social ${ }^{2}$ fue desplazado a un plano secundario dentro de la agenda pública del gobierno. Del turismo social se pasó a un turismo especial destinado a los sectores sociales más vulnerables, "los pobres". De esta manera, se retornaba a la desigualdad social tan ambicionada por las fracciones liberales del gobierno. Por el otro, se comienza a asignar mayor importancia al turismo internacional al concebirlo como "factor de desarrollo", todo ello bajo la influencia de la "doctrina" difundida por Naciones Unidas sobre la importancia del turismo internacional, especialmente para los países subdesarrollados ${ }^{3}$.

Durante el gobierno de Perón (1943-1955) la política turística había tenido como propósito hacer efectiva y concreta la Justicia Social ${ }^{4}$. Para Perón la "justicia social" significaba transformar el status y las condiciones materiales de las masas. El nacionalismo de Perón ${ }^{5}$ se identificaba con el progreso económico y social de las clases populares (Rock, 1993). De este modo, el peronismo había intentado crear una nueva dignidad y el orgullo de pertenecer al "pueblo" (como contrapuesto a oligarquía), creando en el imaginario popular la representación de una edad de oro (Capanegra, 2006). Mediante el impulso y desarrollo dado principalmente al turismo social, las clases populares habían tenido la posibilidad de acceder fácilmente a mayor tiempo libre tras la conquista de las vacaciones como un derecho. Así, en los dos planes quinquenales (19471951 y 1952-1957) se puede observar la política turística que adoptó el peronismo, siempre circunscripta al área social como estrategia para hacer efectiva la Justicia Social.

Pero con el nuevo gobierno de facto, se inició un proceso para desperonizar también al turismo. Esto se puede observar en diferentes manifestaciones que visibilizan el desprecio que sentían los facciones liberales por todo aquello que tuviera que ver con el peronismo. Esto queda ilustrado en el relato que realiza Fernández Balzano (1973: 16):

"Las Unidades Turísticas fueron desmanteladas cuando la llamada Revolución Libertadora asumió el poder. Se quemaron sábanas frazadas, alfombras, cortinas... por el sólo hecho de llevar el sello Fundación Eva Perón. La depredación llegó incluso a las unidades de alta montaña: Puente del Inca y Las Cuevas, donde se llegó a tirar al río Mendoza vajilla y cristalería importada de Finlandia y Checoslovaquia".

1 Cabe consignar que como consecuencia de las políticas públicas en curso en este período, en el país se inicia una creciente movilidad social que dio origen a una clase media acomodada, "los nuevos ricos", dando lugar al turismo popular. Así, el turismo social y el turismo popular constituyeron la etapa del turismo masivo en Argentina (Wallingre, 2007) y que se consolidó en las décadas del sesenta y setenta (Pastoriza, 2011). Este turismo popular conformaría también el turismo interno. Se entiende por turismo interno los desplazamientos que efectúan los visitantes residentes dentro del territorio económico del país (Tomillo Noguero, 2010).

2 El turismo social implicó la inclusión de los trabajadores (obreros y empleados), maestros y estudiantes a la práctica turística (Pastoriza, 2002).

3 En los primeros años de la II posguerra el intenso crecimiento de viajes internacionales advirtió al Consejo Económico y Social de Naciones Unidas la necesidad de convocar a una Conferencia Internacional sobre el Turismo y los Viajes Internacionales. Esta se celebró en 1963 en Roma con la participación de todos los Estados miembros. En esta Conferencia se proclamó la tesis sobre la función e importancia del turismo internacional como factor de desarrollo, especialmente para los países subdesarrollados, debido a la capacidad de atenuar el déficit estructural en sus balanzas de pagos. Se lo concibe como materia invisible de exportación. Luego se elaboraron manuales y recomendaciones y se brindó asistencia técnica desde Naciones Unidas (Capanegra, 2011).

4 Según David Rock (1993) en términos prácticos la "justicia social” era un eufemismo cuyo significado principal era la configuración de un sistema sindical controlado por el Estado, que tendría que evitar la penetración comunista, proveyendo simultáneamente a los nacionalistas de instrumentos para establecer su dominación política. Pero, en particular los nacionalistas y Perón discrepaban en la forma de entender la "justicia social". En la versión nacionalista, ésta implicaba "tutela", "jerarquía y "valores".

5 Sobre la relación entre nacionalismo y peronismo ver Rubinzal, M. (2005) La derecha y la cuestión social en la Argentina. La cuestión obrera en la perspectiva del nacionalismo en Buenos Aires (1935-1943), Tesis de licenciatura (Santa Fe, Universidad Nacional del Litoral). 
Asimismo es posible observar las ideas derechistas liberales en documentos e informes oficiales. Así, en un trabajo editado por el Ministerio de Trabajo y Previsión en 1956, bajo el título Tiempo libre y colonias de vacaciones, en su introducción se plantea que se publican esos apuntes con la aspiración de realizar un aporte útil como punto de partida para una reestructuración del sistema nacional de aprovechamiento del tiempo libre de los trabajadores. En el capítulo IV Estado actual del turismo social, se puede observar la necesidad de que el gobierno militar comenzara a promover cambios en las concepciones, criterios y políticas turísticas nacionales de cara al futuro. Se menciona la necesidad de promover el turismo extranjero "para la reconstrucción económica nacional" dado que se lo considera como una "industria de exportación invisible" siguiendo el camino iniciado por los países europeos. Así, es posible advertir el giro en la forma de concebir al turismo. Con ello se estaría sentando las bases sobre la función que se le asignaría al desarrollo del turismo en Argentina años más tarde por sus beneficios principalmente económicos, desplazando al turismo social y al turismo interno a un plano secundario.

De este modo, se observa la omisión por parte del gobierno militar a las políticas públicas sobre turismo social llevada a cabo por el peronismo, o su eventual mención en forma tangencial. Además, se deja en claro, en el caso de los trabajadores, que aun cuando cuenten con una legislación sobre vacaciones pagas, no poseen los medios económicos y financieros suficientes para afrontar los gastos que demanda la realización de un viaje de descanso, y el Estado tampoco estaría en condiciones de financiarlo. Los trabajadores, en su condición de "pobres", dejarían de contar con este beneficio que le había dado el gobierno peronista. De esta manera, se observa cómo las ideas derechistas liberales iban impregnando las políticas públicas en materia de turismo que el gobierno de facto de la Revolución Libertadora quería comenzar a imponer en el país.

Otro indicador de la nueva función que se le estaba comenzando a asignar al turismo fue la creación de la Dirección Nacional de Turismo (DNT), mediante los decretos leyes 6325 (11-04-56) y 8014 (16-06-57), dejando de formar parte así de la Dirección Nacional de Parque Nacionales. Como entidad autárquica dependería de la Secretaría de Transportes del Ministerio de Obras y Servicios Públicos, con el fin de ejercer todas las funciones esenciales al fomento y organización del turismo interior y exterior hacia el país y de promover el turismo educacional y social; dando las bases técnicas y científicas necesarias para que la acción del Estado asegure la valoración, estímulo y aprovechamiento de los elementos e intereses turísticos, a fin de ponerlos al servicio del "pueblo" y de la "economía" de la nación. Su régimen financiero la facultaba para administrar sus propios fondos y los asignados al Fondo Nacional de Turismo. La DNT inició su actividad el $1^{\circ}$ de febrero de 1958. Sin embargo, una de las peculiaridades más negativas de su gestión haya sido la constante sucesión de directores. Durante los quince años de actividad se continuaron cerca de dieciséis directores (Fernández Balzano, 1973). La falta de continuidad de éstos posiblemente explique la brecha entre la política enunciada y la política efectivamente implementada en turismo durante este período.

Durante el gobierno democrático de Arturo Frondizi (1958-1962) ${ }^{6}$ se aprobó la Ley de Turismo $\mathrm{N}^{0}$ 14574. En el debate parlamentario sobre el proyecto de ley ${ }^{7}$ es posible observar la visión que se tenía del turismo como política de estado al concebirlo como estrategia de política económica. En este sentido, el Senador de la UCR, por Capital Federal, Dr. Armando Luis Turano expresaba que era necesario "contribuir a su desarrollo" entendiéndolo como un

6 Cuando Arturo Frondizi llegó a la presidencia en 1958, lo hizo con el apoyo de los nacionalistas. Sostenían que Frondizi habría de ser "fiel a la tradición del país, a su soberanía y a la justicia social". Pero apenas asumió la presidencia, los deseos de los nacionalistas se frustraron nuevamente. Frondizi asumió una posición anticlerical en torno a la cuestión educativa, abandonó su programa nacionalista en el orden económico y estableció una alianza con las corporaciones multinacionales (Rock, 1993).

7 Se ha tomado para su análisis la cita publicada por Capanegra (2011) en la ponencia "La construcción social del turismo como factor de desarrollo, Argentina 1958-2005”. XI Jornadas Internacionales y V Simposio Internacional de Investigación-Acción en Turismo, Argentina. 
acto de "patriotismo". Así, se fue consolidando la idea de "desarrollar" el turismo, en tanto es considerado como otra "industria" más con capacidad de exportación. Esto permitiría generar nuevos beneficios económicos y financieros a fin de equilibrar la balanza de pagos, a partir del ingreso de divisas al país. Se sostenía que el mayor problema que afrontaba la nación era la falta disponibilidad de medios financieros. Se entendía que existían tres fuentes para equilibrar y llegar al superávit en la balanza de pagos: la actividad agrícola ganadera, la industria y el turismo. Y en particular este último se constituía en el medio menos dificultoso y que más rápido reactivaría la economía nacional. Se hacía evidente, así, las potencialidades del desarrollo turístico. La necesidad del gobierno desarrollista de Frondizi de contar con importantes inversiones de origen extranjero, dada la insuficiencia de capitales de origen nacional, lo llevó a adoptar un programa de corte liberal en lo económico, incluyendo al turismo dentro de las políticas económicas.

\section{6-1976: la planificación para el desarrollo como política turística}

El golpe de Estado de 1966 que derrocó a Illia, autodenominado la "Revolución Argentina", catapultó al General Onganía al control casi total del Estado. El "Acta de la Revolución Argentina" usaba, como sus predecesores, el lenguaje de los nacionalistas: "una pésima conducción de los negocios públicos por el gobierno anterior", "la ruptura de la unidad espiritual del pueblo argentino", "la apatía y la pérdida del sentir nacional", "la ausencia de orden y disciplina". Desde el principio su gestión se caracterizó por un accionar paternalista, fuertemente autoritario, un carácter tecnocrático muy marcado y apolítico (Romero, 2013). Con la idea de que las Fuerzas Armadas sólo podrían cumplir con su objetivo de defender la seguridad nacional convirtiéndose en agentes de la modernización económica y social, entendían que en el "desarrollo económico" se encontraba la llave de la seguridad y el mejor reaseguro en contra de la subversión, de acuerdo a la Doctrina de Seguridad Nacional. Con esta convicción el gobierno creó el Consejo Nacional de Desarrollo (CONADE) y el Consejo Nacional de Seguridad (CONASE), señalando que ambos organismos debían trabajar de manera conjunta (Rock, 1993).

En este período, el organismo público de turismo continuó mutando su figura orgánica de acuerdo a la visión del gobierno de turno sobre la forma de gestionar el turismo, a fin de que contribuya al desarrollo económico del país. El 6 de junio de 1967, al crearse la Secretaría de Difusión y Turismo, por Decreto 3921/67 y Ley 17301, se dispuso la transferencia de la DNT a dicha Secretaría. Sin embargo, la complejidad de las actividades de difusión no permitieron dedicarle una debida atención al turismo. Es por ello que se decide crear en 1971 la Secretaría de Turismo, directamente vinculado a la presidencia de la Nación. Creada por Decreto 1472/71, su estructura orgánica es aprobada con la inclusión de una Dirección General de Planeamiento y Desarrollo y una Dirección General de Asuntos Turísticos, por decreto 6348/71, al entender que su estructura permitirá alcanzar los objetivos y metas establecidos en el Plan Nacional de Desarrollo y Seguridad 1971/75 (Fernández Balzano, 1973). De a poco se va consolidando una gestión centrada en la planificación para el desarrollo del turismo bajo los lineamientos que imponía la Doctrina de Seguridad Nacional.

Es por ello que se considera que en este período se dio inicio a la planificación económica del turismo en el país, a fin de impulsar su desarrollo. En rigor, la consideración de la planificación como un instrumento necesario para el desarrollo económico de Argentina, ya se había incluido en las discusiones entre los intelectuales a comienzos de los años treinta; y luego a mediados de la década del cuarenta con el trabajo de Adolfo Dorfman, quien incorpora la discusión internacional sobre planificación y desarrollo disponible hasta el momento. Si bien durante el gobierno peronista se había impulsado la planificación a escala nacional, justificada a la luz de la necesidad de prevenir a la economía local de las fluctuaciones del comercio exterior (Rougier y Odisio, 2016), y se había incorporado en ella al turismo, es recién en la década del sesenta cuando se inicia su planificación sectorial. 
La planificación como instrumento al servicio del ordenamiento turístico había tenido su origen en los países centrales alrededor de 1955, cuando los estados tomaron conciencia que la rentabilidad privada no bastaba para garantizar el desarrollo turístico de las regiones. Así, y de acuerdo a lo planteado por Gemelli (1986), en Argentina esta tendencia aparece recién hacia mediados de la década del sesenta. En efecto, el organismo nacional de turismo conformó un equipo interdisciplinario para elaborar los primeros estudios de base en pos del desarrollo turístico del país. A partir de ahí los organismos de turismo de las provincias, por sí mismos o a través del Consejo Federal de Inversiones, también comenzaron a producir los primeros estudios, planes y proyectos de desarrollo turístico. A estos emprendimientos se sumaron los aportes realizados por los organismos internacionales a través de la asistencia técnica de capacitación para la puesta en valor de los principales recursos turísticos del país (Gemelli, 1986).

El primer antecedente de planificación turística a nivel nacional lo constituye las Bases metodológicas para la planificación del turismo como factor de desarrollo regional, en el año 1967, trabajo dirigido por Georges Celestin y José Manuel Bringas. Este documento corresponde al Informe de la Misión de asistencia técnica, efectuada por expertos de la Organización de Estados Americanos (OEA) a un equipo interdisciplinario de la Facultad de Arquitectura y Urbanismo de la Universidad de Buenos Aires (UBA) asignado a la Dirección Nacional de Turismo. Este equipo buscaba estudiar la incidencia del fenómeno turístico en las economías regionales. Al año siguiente, en 1968, la Dirección Nacional de Turismo elabora otro informe denominado Primer documento de trabajo, con asesoramiento técnico de la OEA. Este documento se confecciona a modo de base para la planificación del desarrollo turístico del país. Entre sus objetivos figuraba la confección de una metodología para la planificación del desarrollo turístico de las áreas y zonas turísticas identificadas, entendiendo al turismo como el motor de desarrollo regional. Estos dos documentos se consideran fundamentales en tanto representan la consolidación del desarrollo turístico en el país al elaborar las bases conceptuales y teóricas para su planificación a nivel provincial, regional y/o nacional (Capanegra, 2015).

Por otra parte, también se firma un convenio entre la Facultad de Arquitectura y Urbanismo de la UBA y la Dirección Nacional de Turismo, con el fin de diseñar una política pertinente para el desarrollo turístico. En este documento se argumenta que a partir de ahí comenzaría la metódica planificación central del turismo. Primero se realiza un estudio para la elaboración de un Plan de desarrollo turístico de Misiones, y luego se elaboró el Plan de Desarrollo Turístico del Noroeste Argentino en colaboración con el CONADE ${ }^{8}$, contando con la asistencia técnica de Naciones Unidas. Si bien durante este lapso de tiempo se elaboraron los documentos mencionados, se puede afirmar que hasta entonces no existiría un plan turístico definitivo. Además, el turismo tampoco aparecía integrado como sector en la planificación general de desarrollo del país (Wallingre, 2007).

En 1971 el CONADE y el CONASE elaboran el Plan Nacional de Desarrollo y Seguridad 1971/75. Este plan incluye el tema Turismo en su capítulo XVII (pp. 219 - 221). En la introducción se mencionan muy brevemente las características del turismo en el país, la evolución de la demanda turística externa e interna, de la oferta turística y los desajustes entre ambas que señalan las características específicas del desarrollo del sector. Entre los objetivos del plan se destacan: promover el desarrollo del turismo interno, especialmente el social; promover el turismo internacional como medio de proyección del país al exterior y como fuente de divisas; asegurar la preservación y promover el conocimiento de las bellezas naturales del país, su flora y su fauna; entre otros. De este modo, se observa que se vuelve a la idea de fomentar principalmente el turismo internacional por posibilitar el ingreso de divisas al país, en tanto la promoción del turismo interno quedaría centrada en el turismo social, que ahora lo incluye, y en un segundo plano.

8 La CONADE inició una serie de estudios diagnósticos sobre las características y posibilidades del desarrollo del turismo en diferentes regiones del país e intervino en la formulación de diversos planes nacionales de desarrollo, contando con distintas asistencias técnicas de Naciones Unidas (Capanegra, 2011). 
En 1973, tras siete años de gobiernos militares, el peronismo volvía a gobernar el país. De esta manera los nacionalistas comenzaron inmediatamente a reconstruir las instituciones corporativas que habían utilizado en el período de 1946 a 1955 (Rock, 1993). En ese año Fernández Balzano elabora un informe para los Equipos Nacionales Tecnológicos Peronistas denominado El turismo en la República Argentina desde la Fundación Eva Perón hasta la creación de una secretaría especifica. En este documento se plantean los lineamientos de base para el desarrollo de una firme política en materia de turismo de corte fundamentalmente nacionalista. Entre sus argumentos se destacan: el establecimiento del rol de la autoridad turística nacional el cual deberá ser esencialmente nacionalista y no liberal; la necesidad de fomentar principalmente al turismo interno dado que propicia el conocimiento de la "Patria" y el de los compatriotas, pero no así el turismo externo el cual se deberá "combatir" ya que significa una evasión de capital; y por último, la conveniencia del turismo receptivo (internacional) en tanto aporta divisas extranjeras al país. El aparato oficial debía ser dotado de una dinámica justicialista, extendiendo sus beneficios a todos los sectores sociales, porque "El hombre debe ser sujeto y protagonista del Turismo y no un mero objeto de la explotación turística" (Ibid.: 33). Fundamentalmente, el turismo debía insertarse al servicio de la patria y al de los compatriotas. Se plantea la necesidad de consolidar una "auténtica industria" del turismo y para ello se requiere de una planificación con "mentalidad científica".

También, en ese mismo año el nuevo gobierno democrático elabora el Plan Trienal para la Reconstrucción y la Liberación Nacional (1974-77). En este plan se incluye muy escuetamente el tema turismo entre los objetivos y metas a alcanzar en los distintos aspectos de importancia en la vida económica y social del país. La propuesta comprende dos niveles: Turismo social y el Plan de desarrollo turístico propiamente dicho. Este último estaba orientado en dos direcciones: promover el turismo interno y el flujo turístico internacional, para lo cual se debería desarrollar la infraestructura, el equipamiento y los servicios y acondicionar los centros turísticos a fin de satisfacer esos dos tipos de demanda (Gemelli, 1986). Este plan, si bien se ajusta al contexto actual al otorgarle importancia al turismo internacional, le da mayor relevancia al turismo interno y recupera el turismo social para la clase trabajadora y de menores recursos.

Al año siguiente, en 1974, el Ministerio de Bienestar Social, la Secretaría de Estado de Deportes y Turismo, y la Subsecretaría de Turismo definen los objetivos generales del plan que consistían en diseñar estrategias para los dos tipos de turismo, interno y externo. Luego de analizar la situación de la oferta, de la demanda, de la balanza de pagos referidos al ingreso y egreso de viajeros y de la legislación vigente, se proponía un programa de Desarrollo Turístico. La estructura turística que se planteaba para el desarrollo del sector se basaba en la zonificación del país en áreas de valor nacional e internacional atendiendo a los dos tipos de demanda y en ellas se localizarían los mayores esfuerzos de planificación e inversiones. Sin embargo, todos estos planes mencionados fueron afectados por la falta de recursos y la mayoría de los proyectos no pudieron ejecutarse (Wallingre, 2007).

\section{6-1983: la política turística sin planificación}

El golpe de Estado del 24 de marzo de 1976 fue promovido por una alianza cívicomilitar. Estos tenían un diagnóstico común respecto de la naturaleza de la crisis argentina y de los instrumentos que debían ser aplicados para concluirla. Entendían que la solución a la larga "decadencia nacional" sólo podía arribarse a través de la concreción de dos objetivos inseparables: la denominada "lucha antisubversiva" y la "normalización" económica. En la distribución de cargos dentro del gabinete, la cartera de economía quedó bajo el mando de un funcionario civil, el Dr. José Alfredo Martínez de Hoz, un economista de ideas liberales, determinando así la orientación que tendría la política económica del nuevo gobierno de facto. Los objetivos perseguidos por esta política comenzaron a mostrar su incompatibilidad con la ideología nacionalista al que adherían gran parte de los elencos militares. El "antiestatismo" 
del nuevo equipo económico suscitaba fuertes molestias entre quienes entendían que el Estado debía ser un activo promotor del desarrollo económico y actor privilegiado de la planificación (Canelo, 2008).

En efecto, los nacionalistas con sus concepciones desarrollistas también habían encontrado adeptos entre los "burócratas" militares y civiles, y se hallaban al frente del complejo militarindustrial y de las empresas del Estado. Eran estos miembros de la corriente "industrialista" que le confería a las Fuerzas Armadas objetivos extramilitares, vinculados con el desarrollo económico y social. Este sector había sumado a su repertorio clásico (la crítica al individualismo liberal y a la partidocracia, la apología de la autoridad, y el orden y la unidad del cuerpo nacional) un particular entusiasmo por el industrialismo y la modernización económica del país. A la vez, su anticomunismo y antiperonismo, y sus concepciones corporativistas en el plano político, los llevaban a rechazar cualquier acercamiento con las organizaciones políticas y con los sindicatos (Canelo, 2008).

Los objetivos de esta política económica de corte liberal, eran incompatibles con los valores e intereses de los militares nacionalistas, quienes entendían que el Estado debía ejercer un rol importante en la promoción económica a la vez que ser un actor privilegiado de la planificación. Así, entre fines de 1976 y mediados de 1977 se crea el Ministerio de Planeamiento, impulsado por las fracciones nacionalistas. Esta creación generó una fuerte reacción de la opinión pública liberal ya que entraba en contradicción con la "filosofía económica" del Proceso de racionalización de la administración pública, al recuperar la idea de planificación estatal. El General Díaz Bessone, designado como responsable de esta cartera, redactó el primer plan político del régimen, el Proyecto Nacional. En particular sobre este documento, Canelo (2008: 11) sostiene que dentro del imaginario de sus autores "convivían tanto componentes del más rancio liberalismo conservador como del nacionalismo más corporativo".

En definitiva el Proyecto Nacional, hasta ese momento, era coherente con el retraimiento social que requería el plan económico de Martínez de Hoz y el accionar represivo del gobierno. En mayo de 1977, los militares apoyaron las propuestas de planeamiento mediante el documento Plan Nueva República, elaborado por el Secretario General del Estado Mayor del Ejército. El mismo, a tono con el desarrollismo del Proyecto Nacional, recomendaba "encarar por el sector público el incremento de la infraestructura requerida para el desarrollo" y el "desarrollo de industrias básicas" y "polos de desarrollo" en el interior del país (Canelo, 2008).

En este contexto, sin embargo, la política turística careció de la elaboración e implementación de un Plan específico para su desarrollo. En este sentido, y a partir de la falta de concreción de los planes elaborados anteriormente, en 1977 el organismo oficial de turismo reconocía que la planificación turística argentina había sido esporádica y parcial (Wallingre, 2007). Se consideraba que esta parcialidad se debía a que, hasta ese momento, no se había podido planificar el turismo dentro del marco general de la planificación nacional.

En ese mismo año, la Subsecretaría de Turismo con la participación de técnicos del Cicatur-OEA, elaboró un documento denominado El Turismo en la República Argentina. Este documento tuvo por objetivos, por un lado, poner en evidencia lo que el turismo representaría en el presente y futuro del país; y por el otro, servir de base para investigaciones y estudios que los enriqueciera y complementase. Además, buscaba elaborar futuros planes sectoriales que se insertasen en la planificación nacional. Constaba de tres secciones: la primera definía al turismo, la segunda analizaba la evolución del turismo en el país, y la tercera parte contenía y justificaba una propuesta conceptual. Los resultados del documento dan cuenta que el turismo era considerado un sector alternativo en el desarrollo socioeconómico nacional, y entendía que delinear una política turística no era una tarea exclusiva del sector ni público ni privado.

Asimismo, y durante el Proceso de Reorganización Nacional, la Subsecretaría de Turismo organizó una serie de Reuniones Nacionales de Turismo y se elaboraron informes. De las trece reuniones celebradas entre 1976 y 1980, sólo en las dos primeras reuniones se trabajó sobre la 
planificación en el turismo, en el resto de las reuniones se trataron temas como: señalamiento turístico, interpretación de la naturaleza, inventario turístico, áreas forestales de recreación y otras en función de la planificación turística.

En la primera reunión se elaboró el documento El planeamiento turístico: su difusión dentro del concepto actual del turismo. Ese informe daba cuenta de la importancia del mismo para el turismo, y partía de definir el planeamiento como la proyección de un futuro deseado y la determinación de los medios efectivos para lograrlo; considerando que de todas las clases y jerarquía que forman un planeamiento, las que han recibido un análisis más profundo son las evaluaciones de inversión.

En la segunda reunión, también celebrada en 1976, se elaboró el informe Primeras bases para el Plan Nacional de Desarrollo Turístico. Esa propuesta partía de la definición del turismo, teniendo en cuenta para la formulación de los objetivos nacionales las consecuencias, tanto económicas como sociales, que tiene esta actividad. Como objetivo internacional buscaba influir positivamente sobre la balanza de pagos. Proponía una estrategia para la captación de turismo receptivo, actuando prioritariamente sobre los países que componen la región sudamericana.

Esto hace evidente que las fracciones nacionalistas del elenco militar, aun habiendo estado preocupadas por la planificación estatal, creando para ello un ministerio abocado a tal fin, no parece que le hayan otorgado una mayor significación a la necesidad de generar un plan sectorial para el turismo. En definitiva, para el Proceso de Reorganización Nacional, y en línea con el ideario neoliberal, el fomento del turismo internacional ya sería un objetivo incuestionable para su política económica, en tanto contribuiría a equilibrar su balanza comercial, aunque exento de una planificación sectorial. Además, el retraimiento social que se produjo tras la implantación del plan económico de Martínez de Hoz no dio a lugar para que el turismo interno y el turismo social se constituyeran en temas de agenda política para el gobierno de facto.

\section{Conclusiones}

El presente trabajo ha pretendido realizar una primera aproximación a la problemática de las políticas públicas en turismo implementadas por los gobiernos de derecha de Argentina, durante gran parte de la segunda mitad del siglo XX. Es por ello que se entiende que no se ha agotado el análisis pasible de realizarse atendiendo sus diversas aristas o planteado desde otras perspectivas que permitan echar más luz sobre dicha problemática. A partir de los trabajos realizados por Pastoriza, Piglia, Schenkel y Capanegra, se ha intentado complementar el análisis de las políticas turísticas incorporando la identificación de las ideas derechistas, distinguiendo entre nacionalistas y liberales, a través de la observación de varios instrumentos de políticas públicas y de documentos oficiales durante tres momentos históricos.

Así, se pudo observar, en el período 1955-1966, las primeras manifestaciones en las políticas públicas del cambio de concepción del turismo como factor de desarrollo para el país, bajo los lineamientos fijados por la Doctrina de Seguridad Nacional. Esta veía en el desarrollo económico el instrumento para luchar contra la subversión. Para ello, las fracciones liberales impulsaron al turismo internacional, al concebirlo como una industria de exportación que permitiría el ingreso de divisas; contribuyendo, de esta manera, a la reconstrucción económica nacional. De este modo, en la configuración de la política pública el turismo internacional desplazaría al turismo social y al turismo interno a un segundo plano. Sin embargo, contrariamente a lo esperado, el turismo internacional no pudo cumplir su cometido. La balanza de pagos en el rubro "Viajes al y del exterior" comienza a ser deficitaria en 1958, llegando a alcanzar los cuarenta y nueve millones de dólares negativos, en 1964.

En el período 1966-1976, es cuando definitivamente se institucionaliza ésta concepción de los organismos internacionales y el turismo internacional se resignificaría como política económica y se plantearía la necesaria planificación para su desarrollo. Durante este período se elaboraron documentos de bases para la planificación específica del turismo y dos planes 
generales. En el Plan Nacional de Desarrollo y Seguridad, de 1971, se impulsaba el fomento del turismo internacional, y el turismo interno y social quedaban nuevamente relegados en un plano secundario. Este documento da cuenta de la ideología derechista liberal en la concepción del turismo como instrumento de desarrollo, en tanto es utilizado como estrategia para el ingreso de divisas mediante el turismo internacional. En 1973 el peronismo elabora el Plan Trienal, de corte nacionalista, donde se reivindicaría al turismo social para los trabajadores y concebiría un Plan de desarrollo turístico que incluía al turismo interno e internacional. Así, entre los años sesenta y setenta, Argentina llegó a ocupar el primer puesto en movimientos turísticos internos de Latinoamérica, en tanto el turismo receptivo internacional fue creciendo llegando a superar los novecientos mil turistas en 1975.

Finalmente, durante el Proceso de Reorganización Nacional (1976-1983), caracterizado por una política económica liberal, el turismo internacional siguió manteniendo su importancia por posibilitar el equilibrio de la balanza de pagos. Sin embargo, esto no se vio reflejado en la misma. Desde fines de la década del setenta y principios de los ochenta el turismo emisor tuvo un importante crecimiento, en tanto el turismo receptivo internacional no sufrió retracción pero tampoco tuvo un crecimiento sostenido. Frente a la crisis económica y social derivada de la implementación del plan económico impuesto por la dictadura militar, el turismo interno y el turismo social no se constituyeron en temas de agenda política para el gobierno irruptivo. Por otra parte, la significación que la fracción nacionalista del gobierno militar le otorgó a la planificación, creando para ello un Ministerio especial, no llegó al turismo, quedando esta actividad sin el andamiaje de la planificación sectorial. Se tendría que esperar recién hasta 1984, cuando el reciente gobierno democrático de Alfonsín elaboraría Bases para un Plan Federal de Turismo, el cual, durante más de veinte años, se constituyó en fuente de inspiración y base para planes posteriores como los de la década del noventa.

En suma, los gobiernos de derecha en Argentina no fueron cuerpos monolíticos ni homogéneos, todo lo contrario. En sí los elencos gubernamentales se caracterizaron por ser heterogéneos, y a veces hasta contradictorios, y con ello también sus políticas públicas. A partir de los documentos analizados se observa que es durante el período 1955-1983 donde no sólo se incorpora al turismo en la agenda política del país, sino también que adquiere un nuevo significado en la política pública desde una perspectiva principalmente económica. En definitiva, el cambio en la concepción del turismo como política pública habría sido impulsado desde un ideario derechista con una preeminencia del tipo liberal, especialmente en la faz económica, por sobre el de corte nacionalista, particularmente en la faz social. 


\section{Bibliografía}

Argentina. Consejo Nacional De Desarrollo; Consejo Nacional De Seguridad. 1971, Plan Nacional de Desarrollo y Seguridad 1971/75, Buenos Aires.

Argentina. Ministerio De Trabajo y Previsión. 1956, Tiempo libre y colonias de vacaciones, Buenos Aires.

Argentina. Poder Ejecutivo Nacional. 1973, Plan trienal para la reconstrucción y la liberación nacional, 19741977, Buenos Aires.

Bohoslavsky, E. 2009, El complot patagónico. Nacionalismo, mitos conspirativos y violencia en el sur de Argentina y Chile (siglos XIX y XX), Prometeo Libros, Buenos Aires.

Borges, N. 2007, “A doutrina de segurança nacional e os governos militares", en: Ferreira, J. et al. (Eds.), $O$ Brasil republicano 4, Civilização Brasileira, Rio de Janeiro, pp. 13-42.

Buchrucker, C. 2003, "Identidades nacionales y cultura política antidemocrática. Trayectorias históricas del Cono Sur en el siglo XX", Congreso La construcción de las identidades nacionales en el mundo hispánico, Valencia, España.

Canelo, P. 2008, "Las dos almas del Proceso. Nacionalistas y liberales durante la última dictadura militar", $I V^{o}$ Jornadas de Trabajo sobre Historia Reciente, Rosario, Argentina.

Castagnola, J. L. y Mieres, P. 1996, "La ideología política de la dictadura", en: AAVV, El Uruguay de la dictadura. 1973-1985, ediciones de la Banda Oriental, Montevideo, Uruguay, pp. 73-108.

Capanegra, A. 2015, "Turismo y política en Argentina 1946-1986. De la agenda social a la agenda económica", XV Jornadas Interescuelas. Departamentos de Historia, Comodoro Rivadavia, Argentina.

2011, "La construcción social del turismo como factor de desarrollo, Argentina 1958-2005", XI Jornadas Internacionales y V Simposio Internacional de Investigación-Acción en Turismo, Mar del Plata, Argentina.

2010, "El desarrollo turístico como estrategia política de Estado: de la política en turismo a la política turística. Argentina 1900-1975", en: Aportes y transferencias 14(1), pp. 23-42.

2006, "La política turística en Argentina en el siglo XX", en: Aportes y transferencias 10(1), pp. 43-61.

Fernández Balzano, O. 1973, El turismo en la República Argentina desde la Fundación Eva Perón hasta la creación de una secretaría específica, Estudio argentino de relaciones públicas, Buenos Aires.

Gemelli, A. 1986, Antecedentes de la planificación turística en Argentina, Consejo Federal de Inversiones, Buenos Aires.

Ley Nacional $\mathrm{N}^{\circ}$ 14574. 1958, Ley Nacional de Turismo.

Mc Gee Deutsch, S. 1997, "What difference does Gender make? The extreme right in the ABC countries in the era of fascism", Estudios Interdisciplinarios de América Latina y el Caribe, Tel Aviv, Israel.

Novaro, M. 2013, Historia de la Argentina, 1955-2010, Siglo XXI, Buenos Aires.

Oliveira, C. F. de 2008, "IPÊS e IBAD: A crise política da década de 60 e o advento do Golpe Civil-Militar de 1964", en: Revista Eletrônica História em Reflexão, 2(3), pp. 1-33.

Pastoriza, E. 2012, "Nuevos objetos de la historia: los estudios turísticos en una perspectiva comparada", Anuario IEHS, 27, pp. 323-330.

2011, La conquista de las vacaciones. Breve historia del turismo en la Argentina, Edhasa, Buenos Aires.

2002, "Turismo social y acceso al ocio: el arribo a la ciudad balnearia durante las décadas peronistas (Mar del Plata, 1943-1955)”, en: Pastoriza, E. (Ed.), Las puertas al mar: consumo, ocio y política en Mar del Plata, Montevideo y Viña del Mar, Biblos, Buenos Aires, pp. 89-113).

Piglia, M. 2014, Autos, rutas y turismo: El Automóvil Club Argentino y el estado, Siglo Veintiuno Editores, B Aires.

2012, "Turismo y obra pública. José María Bustillo y la política turística del gobierno de Fresco", en: Revista de Historia Bonaerense 19(40), pp. 14-23.

2011, "The awakening of tourism: the origins of tourism policy in Argentina, 1930-1943", en: Journal of Tourism History 3(1), pp. 57-74.

Rock, D. 1993, La Argentina autoritaria. Los nacionalistas, su historia y su influencia en la vida pública, Ariel, B Aires.

Romero, J. L. 2013, Breve historia de la Argentina, Fondo de Cultura Económica de Argentina, Ciudad Autónoma de Buenos Aires.

Rougier, M. y Odisio, J. 2016, "Introducción | Planificación y desarrollo en perspectiva histórica”, en: M. Rougier y J. Odisio (Comps.), Estudios sobre planificación y desarrollo (pp. 9-26). Buenos Aires: Lenguaje claro editora. 
Rubinzal, M. 2005, La derecha y la cuestión social en la Argentina. La cuestión obrera en la perspectiva del nacionalismo en Buenos Aires (1935-1943), Tesis de licenciatura, Santa Fe, Universidad Nacional del Litoral.

Schenkel, E. 2013, "El turismo social como política estatal en Sudamérica”, en: Revista de Turismo y Patrimonio Cultural, $l(11)$, pp. 173-183.

Tomillo Noguero, F. 2010, "El concepto de turismo según la OMT”, en: Castillo Nechar, M. Epistemología del turismo. Estudios críticos, Trillas, México, pp. 174-201.

Unión del Comercio, la Industria y la Producción 1969, Series estadísticas, UCIP, Mar del Plata.

Wallingre, N. 2007, Historia del turismo argentino, Ediciones turísticas, Buenos Aires. 